\title{
A molecular pore spans the double membrane of the coronavirus replication organelle
}

\author{
Georg Wolff', Ronald W. A. L. Limpens' ${ }^{1}$, Jessika C. Zevenhoven-Dobbe ${ }^{2}$, Ulrike Laugks ${ }^{3}$, Shawn Zheng ${ }^{4}$, \\ Anja W. M. de Jong' , Roman I. Koning' ${ }^{1}$, David A. Agard ${ }^{5}$, Kay Grünewald ${ }^{3,6}$, Abraham J. Koster', \\ Eric J. Snijder ${ }^{2}$, Montserrat Bárcena ${ }^{1 *}$ \\ ${ }^{1}$ Department of Cell and Chemical Biology, Section Electron Microscopy, Leiden University Medical Center, Leiden 2333 ZC, Netherlands. ${ }^{2}$ Department of Medical \\ Microbiology, Molecular Virology Laboratory, Leiden University Medical Center, Leiden 2333 ZA, Netherlands. ${ }^{3}$ Department of Structural Cell Biology of Viruses, Centre for \\ Structural Systems Biology, Heinrich Pette Institute, Leibnitz Institute of Experimental Virology, Hamburg, Germany. ${ }^{4}$ Department of Biochemistry and Biophysics, Howard \\ Hughes Medical Institute, University of California San Francisco, San Francisco, CA 94143, USA. 5Department of Biochemistry and Biophysics, University of California San \\ Francisco, San Francisco, CA 94143, USA. ${ }^{6}$ Department of Chemistry, MIN Faculty, Universität Hamburg, Hamburg, Germany. \\ *Corresponding author. Email: m.barcena@lumc.nl
}

Coronavirus genome replication is associated with virus-induced cytosolic double-membrane vesicles, which may provide a tailored micro-environment for viral RNA synthesis in the infected cell. However, it is unclear how newly synthesized genomes and mRNAs can travel from these sealed replication compartments to the cytosol to ensure their translation and the assembly of progeny virions. Here, we used cellular electron cryo-microscopy to visualize a molecular pore complex that spans both membranes of the double-membrane vesicle and would allow export of RNA to the cytosol. A hexameric assembly of a large viral transmembrane protein was found to form the core of the crown-shaped complex. This coronavirus-specific structure likely plays a critical role in coronavirus replication and thus constitutes a potential drug target.

Severe acute respiratory syndrome coronavirus 2 (SARS-CoV2 ) is the third and most impactful example of a potentially lethal coronavirus infection in humans within the last 20 years (1-3). Coronaviruses are positive-stranded RNA (+RNA) viruses that replicate their unusually large genomes in the host cell's cytoplasm. This process is supported by an elaborate virus-induced network of transformed endoplasmic reticulum (ER) membranes known as the viral replication organelle (RO) (4-7). Double-membrane vesicles (DMVs) are the RO's most abundant component and the central hubs for viral RNA synthesis (5). The DMV's interior accumulates double-stranded (ds) RNA intermediates of viral genome replication and subgenomic mRNAs synthesis $(4,5)$. DMVs may offer a favorable micro-environment for viral RNA synthesis and shield it from innate immune sensors that are activated by dsRNA. Intriguingly, however, coronaviral DMVs have been characterized as compartments that lack openings to the cytosol (4-6), despite the fact that newlymade viral mRNAs need to be exported for translation. Moreover, the coronavirus genome needs to be packaged by the cytosolic nucleocapsid $(\mathrm{N})$ protein, before being targeted to virus assembly sites on secretory pathway membranes (8).

Here, we sought to analyze the structure of coronavirusinduced ROs in their native host cellular environment by electron cryo-microscopy (cryo-EM). The murine hepatitis coronavirus (MHV) is a well-studied model for the genus betacoronavirus, which also includes SARS-CoV, MERS-CoV, and SARS-CoV-2. One advantage of MHV over these class-3 agents is the absence of serious biosafety constraints, enabling its use for in situ cryo-EM studies. We performed electron tomography (ET) on cryo-lamellae prepared by focused ion beam milling cells in the middle stage of MHV infection. The tomograms revealed abundant perinuclear DMVs having an average diameter of $257 \mathrm{~nm} \pm 63 \mathrm{~nm}$ (SD), occasionally interconnected or connected to the ER as part of the reticulovesicular network previously described (Fig. 1, fig. S1, and movie S1) (4-7). In addition, striking macromolecular features that had not been discerned in conventional EM samples became apparent (figs. S2 to S4). The DMV lumen appeared primarily to contain filamentous structures that likely correspond to viral RNA (Fig. 1 and fig. S4). In part, this is expected to be present as dsRNA $(4,5)$, which is supported by the relatively long straight stretches observed in some of these filaments, consistent with the persistence length of dsRNA (9) (fig. S4).

Each DMV contained multiple copies of a molecular complex that spanned both membranes, connecting the DMV interior with the cytosol (Fig. 2A and supplementary text). Such complexes were also found in DMVs in pre-fixed SARS-CoV2-infected cells (Fig. 2B and fig. S5). We surmise that this pore represents a generic coronaviral molecular complex playing a pivotal role in the viral replication cycle. Most likely, it allows the export of newly synthesized viral RNA from the DMVs to the cytosol. Functionally analogous viral complexes 
used for RNA export include those in the capsids of the Reoviridae (10) and, interestingly, the molecular pore in the neck of the invaginated replication spherules induced by flock house virus (11), although none of these is integrated in a double-membrane organelle.

Subtomogram averaging of the double-membranespanning complexes in MHV-induced DMVs revealed an overall 6-fold symmetry (Fig. 2, fig. S6, and movie S2). A cytosolic crown-like structure extended $\sim 13 \mathrm{~nm}$ into the cytosol and was based on a $\sim 24-\mathrm{nm}$ wide platform embedded in the DMV membranes. The two membranes did not fuse and maintained the typical DMV inter-membrane spacing of $\sim 4.5$ $\mathrm{nm}$ (fig. S2). The complex formed a channel that followed its 6 -fold axis. On the DMV luminal side, the channel started with a $\sim 6$-nm wide opening that narrowed toward the cytosol and had two tight transition points (Fig. 2, J and L). The one at the level of the DMV outer membrane (Fig. 2J) was the most constricted, with an opening of $\sim 2-3 \mathrm{~nm}$, but would still allow the transition of RNA strands. Toward the cytosolic space, the complex opened up into the crown-like structure, exposing six cytosolic "prongs." With an achieved resolution of $3.1 \mathrm{~nm}$, we roughly estimate that the complex has a total molecular mass of $3 \mathrm{MDa}$, of which the crown would represent $1.2 \mathrm{MDa}$ (fig. S6).

We then considered the possible constituents of this complex. Coronaviruses express two large replicase polyproteins that are proteolytically cleaved into 16 nonstructural proteins (nsps) (12). Three of these nsps are transmembrane proteins and thus potential candidates to be components of the pore: nsp3 (222 kDa in MHV), nsp4 (56 kDa), and nsp6 (33 kDa), containing two, four and six transmembrane domains (TMDs), respectively (13-15) (Fig. 3A). These nsps engage in diverse homotypic and heterotypic interactions (16) that are thought to drive the formation of double-membrane ROs (1719). Based on its size, the multidomain MHV nsp3 subunit is an attractive putative constituent of the pore. MHV nsp3 consists of a large cytosolic region of $\sim 160 \mathrm{kDa}$ followed by two TMDs and a C-terminal cytosolic domain of $\sim 41 \mathrm{kDa}$ (13). Whereas the TMDs and C-terminal domain are highly conserved, the domain composition and size of the N-terminal part of nsp3 is quite variable among coronaviruses $(16,20)$. Several nsp3 domains may interact with RNA (16), including the conserved N-terminal ubiquitin-like domain 1 (Ubl1, 12.6$\mathrm{kDa}$ ) that binds both single-stranded (ss) RNA (21) and the N protein $(22,23)$.

To investigate whether nsp3 is a component of the DMV molecular pore, we imaged cells infected with a well-characterized engineered MHV expressing nsp3 with an enhanced GFP (EGFP) moiety fused to the Ubl1 domain (MHV- $\triangle 2$-GFP3 (24)) (fig. S7). This mutant lacks nsp2, which is dispensable for replication in cell culture (25). Subtomogram averaging of the pore complexes in these samples (Fig. 3B) revealed the presence of six additional densities on top of the prongs, each representing a mass compatible with that of EGFP (Fig. 3, C to E, and movie S3). These results identified nsp3 as a major constituent of the complex and provided a first clue on its orientation, with the Ubl1 domain residing in the prongs. Six copies of nsp3 can be envisioned to constitute most of the cytosolic crown-like structure ( 1.2 MDa). Likely, other viral and/or host proteins and lipids are also part of the $1.8 \mathrm{MDa}$ inter-membrane platform, with nsp4 and nsp6 being prominent candidates. Indeed, different studies suggest that nsp3nsp4 interactions drive membrane pairing and determine DMV biogenesis and morphology (17-19, 26).

The molecular pores frequently appeared to interact with other macromolecules on both the cytosolic and the DMV luminal side (fig. S8). In the averages, these showed as largely blurred out densities (Fig. 2C), which suggests that the interactions are dynamic. (Fig. 2C). A small region on the luminal side however, had relatively higher density, and was resolved in the unsymmetrized average as a closely associated and slightly off-centered mass (Fig. 2, $\mathrm{M}$ and $\mathrm{N}$, and fig. S6D). This mass can be speculated to be part of the viral replication machinery. The coronaviral replication/transcription complex (RTC) is thought to consist of a subset of relatively small ( 10$110 \mathrm{kDa}) \mathrm{nsps}$ with the RNA-dependent RNA polymerase (nsp12) at its core (27-29). However, some of these subunits may associate with the RTC only transiently and the nsp stoichiometries of the complex are unknown. The luminal partners of the pore complex, prominent as masses varying in shape and size, appeared to interact with the putative RNA content of the DMVs (fig. S8).

The interaction partners of the cytosolic nsp3 prong ranged from chain-like masses to larger assemblies (fig. S8, black arrowheads). The subdomains of the long N-terminal nsp3 domain engage in a range of viral and virus-host interactions $(16,20)$ and, consequently, the list of possible interactors is substantial. Among them, the viral $\mathrm{N}$ protein $(55 \mathrm{kDa})$, which binds to the nsp3 Ubl1 domain $(22,23)$, is a prominent candidate. The Ubl1-N interaction has been proposed to target viral RNA to replication sites early in infection (23), but it may also modulate RNA exit and encapsidation on the cytosolic side of the pore complex. Notably, DMV-rich regions of the cytosol were crowded with protein assemblies with a diameter of $\sim 15 \mathrm{~nm}$ (fig. S9). These strongly resembled the nucleocapsid structure in coronavirus particles, a helical ribonucleoprotein complex (RNP) consisting of the RNA genome and $\mathrm{N}$ protein oligomers (30) (fig. S9).

Our findings suggest a pathway for newly made viral genomic RNA from the DMV interior, via the channel of the pore, to the cytosolic sites of encapsidation. In our model, specific replicase subunits may associate with the pore complex to guide the newly synthesized RNA toward it (Fig. 4A). As proposed for other + RNA viral ROs (11), only positive- 
stranded RNAs would need to be exported, whereas negativestranded templates and/or ds RNA intermediates could remain inside the DMVs. On the cytosolic side, all exported viral mRNAs may associate with the $\mathrm{N}$ protein (Fig. 4B). Alternatively, the accumulating $\mathrm{N}$ protein could serve to select part of the newly made genomes for packaging. The remainder would then be used for translation, together with the much smaller, though much more abundant, subgenomic mRNAs (31). Genome-containing RNPs would travel to the membranes where the viral envelope proteins accumulate and engage in the assembly of progeny virions (Fig. 4C) (32). These bud into single-membrane compartments (Fig. 4D), typically derived from the ER-to-Golgi intermediate compartment (8), and travel along the secretory pathway to be released into extracellular space.

The double-membrane-spanning molecular pore revealed here may constitute the exit pathway for coronaviral RNA products from the DMV's interior toward the cytosol, with the large and multifunctional nsp3 being its central component. Although the exact mode of function of this molecular pore remains to be elucidated, it would clearly represent a key structure in the viral replication cycle that is likely conserved among coronaviruses, and thus may offer a general coronavirus-specific drug target.

\section{REFERENCES AND NOTES}

1. T. G. Ksiazek, D. Erdman, C. S. Goldsmith, S. R. Zaki, T. Peret, S. Emery, S. Tong, C. Urbani, J. A. Comer, W. Lim, P. E. Rollin, S. F. Dowell, A. E. Ling, C. D. Humphrey, W. J. Shieh, J. Guarner, C. D. Paddock, P. Rota, B. Fields, J. DeRisi, J. Y. Yang, N. Cox, J. M. Hughes, J. W. LeDuc, W. J. Bellini, L. J. Anderson, S. W. Group; SARS Working Group, A novel coronavirus associated with severe acute respiratory syndrome. N. Engl. J. Med. 348, 1953-1966 (2003). doi:10.1056/NEJMoa030781 Medline

2. A. M. Zaki, S. van Boheemen, T. M. Bestebroer, A. D. Osterhaus, R. A. Fouchier, Isolation of a novel coronavirus from a man with pneumonia in Saudi Arabia. $N$. Engl. J. Med. 367, 1814-1820 (2012). doi:10.1056/NEJMoa1211721 Medline

3. N. Zhu, D. Zhang, W. Wang, X. Li, B. Yang, J. Song, X. Zhao, B. Huang, W. Shi, R. Lu, P. Niu, F. Zhan, X. Ma, D. Wang, W. Xu, G. Wu, G. F. Gao, W. Tan; China Novel Coronavirus Investigating and Research Team, A novel coronavirus from patients with pneumonia in China, 2019. N. Engl. J. Med. 382, 727-733 (2020). doi:10.1056/NEJMoa2001017 Medline

4. K. Knoops, M. Kikkert, S. H. Worm, J. C. Zevenhoven-Dobbe, Y. van der Meer, A. J. Koster, A. M. Mommaas, E. J. Snijder, SARS-coronavirus replication is supported by a reticulovesicular network of modified endoplasmic reticulum. PLOS Biol. 6 , e226 (2008). doi:10.1371/journal.pbio.0060226 Medline

5. E. J. Snijder, R. W. A. L. Limpens, A. H. de Wilde, A. W. M. de Jong, J. C. ZevenhovenDobbe, H. J. Maier, F. F. G. A. Faas, A. J. Koster, M. Bárcena, A unifying structural and functional model of the coronavirus replication organelle: Tracking down RNA synthesis. PLOS Biol. 18, e3000715 (2020). doi:10.1371/journal.pbio.3000715 Medline

6. H. J. Maier, P. C. Hawes, E. M. Cottam, J. Mantell, P. Verkade, P. Monaghan, T. Wileman, P. Britton, Infectious bronchitis virus generates spherules from zippered endoplasmic reticulum membranes. mBio 4, e00801-13 (2013). doi:10.1128/mBio.00801-13 Medline

7. M. Ulasli, M. H. Verheije, C. A. de Haan, F. Reggiori, Qualitative and quantitative ultrastructural analysis of the membrane rearrangements induced by coronavirus. Cell. Microbiol. 12, 844-861 (2010). doi:10.1111/i.14625822.2010.01437x Medline
8. C. A. de Haan, P. J. Rottier, Molecular interactions in the assembly of coronaviruses. Adv. Virus Res. 64, 165-230 (2005). doi:10.1016/S0065-3527(05)64006-7 Medline

9. J. A. Abels, F. Moreno-Herrero, T. van der Heijden, C. Dekker, N. H. Dekker, Singlemolecule measurements of the persistence length of double-stranded RNA. Biophys. J. 88, 2737-2744 (2005). doi:10.1529/biophysi.104.052811 Medline

10. K. Ding, C. C. Celma, X. Zhang, T. Chang, W. Shen, I. Atanasov, P. Roy, Z. H. Zhou, In situ structures of rotavirus polymerase in action and mechanism of mRNA transcription and release. Nat. Commun. 10, 2216 (2019). doi:10.1038/s41467019-10236-7 Medline

11. K. J. Ertel, D. Benefield, D. Castaño-Diez, J. G. Pennington, M. Horswill, J. A. den Boon, M. S. Otegui, P. Ahlquist, Cryo-electron tomography reveals novel features of a viral RNA replication compartment. elife 6, e25940 (2017). doi:10.7554/eLife.25940 Medline

12. E. J. Snijder, E. Decroly, J. Ziebuhr, The nonstructural proteins directing coronavirus RNA synthesis and processing. Adv. Virus Res. 96, 59-126 (2016). doi:10.1016/bs.aivir.2016.08.008 Medline

13. M. Oostra, M. C. Hagemeijer, M. van Gent, C. P. Bekker, E. G. te Lintelo, P. J. Rottier, C. A. de Haan, Topology and membrane anchoring of the coronavirus replication complex: Not all hydrophobic domains of nsp3 and nsp6 are membrane spanning. J. Virol. 82, 12392-12405 (2008). doi:10.1128/JVI.01219-08 Medline

14. M. Oostra, E. G. te Lintelo, M. Deijs, M. H. Verheije, P. J. Rottier, C. A. de Haan, Localization and membrane topology of coronavirus nonstructural protein 4: Involvement of the early secretory pathway in replication. J. Virol. 81, 1232312336 (2007). doi:10.1128/JVl.01506-07 Medline

15. A. Kanjanahaluethai, Z. Chen, D. Jukneliene, S. C. Baker, Membrane topology of murine coronavirus replicase nonstructural protein 3. Virology 361, 391-401 (2007). doi:10.1016/i.virol.2006.12.009 Medline

16. B. W. Neuman, Bioinformatics and functional analyses of coronavirus nonstructural proteins involved in the formation of replicative organelles. Antiviral Res. 135, 97-107 (2016). doi:10.1016/j.antiviral.2016.10.005 Medline

17. M. M. Angelini, M. Akhlaghpour, B. W. Neuman, M. J. Buchmeier, Severe acute respiratory syndrome coronavirus nonstructural proteins 3,4 , and 6 induce double-membrane vesicles. mBio 4, e00524-13 (2013). doi:10.1128/mBio.0052413 Medline

18. D. Oudshoorn, K. Rijs, R. W. A. L. Limpens, K. Groen, A. J. Koster, E. J. Snijder, M. Kikkert, M. Bárcena, Expression and cleavage of Middle East respiratory syndrome coronavirus nsp3-4 polyprotein induce the formation of doublemembrane vesicles that mimic those associated with coronaviral RNA replication. mBio 8, e01658-17 (2017). doi:10.1128/mBio.01658-17 Medline

19. M. C. Hagemeijer, I. Monastyrska, J. Griffith, P. van der Sluijs, J. Voortman, P. M. van Bergen en Henegouwen, A. M. Vonk, P. J. Rottier, F. Reggiori, C. A. de Haan, Membrane rearrangements mediated by coronavirus nonstructural proteins 3 and 4. Virology 458-459, 125-135 (2014). doi:10.1016/j.virol.2014.04.027 Medline

20. J. Lei, Y. Kusov, R. Hilgenfeld, Nsp3 of coronaviruses: Structures and functions of a large multi-domain protein. Antiviral Res. 149, 58-74 (2018). doi:10.1016/i.antiviral.2017.11.001 Medline

21. P. Serrano, M. A. Johnson, M. S. Almeida, R. Horst, T. Herrmann, J. S. Joseph, B. W. Neuman, V. Subramanian, K. S. Saikatendu, M. J. Buchmeier, R. C. Stevens, P. Kuhn, K. Wüthrich, Nuclear magnetic resonance structure of the N-terminal domain of nonstructural protein 3 from the severe acute respiratory syndrome coronavirus. J. Virol. 81, 12049-12060 (2007). doi:10.1128/JVI.00969-07 Medline

22. K. R. Hurst, C. A. Koetzner, P. S. Masters, Characterization of a critical interaction between the coronavirus nucleocapsid protein and nonstructural protein 3 of the viral replicase-transcriptase complex. J. Virol. 87, 9159-9172 (2013). doi:10.1128/JVl.01275-13 Medline

23. Y. Cong, M. Ulasli, H. Schepers, M. Mauthe, P. V'Kovski, F. Kriegenburg, V. Thiel, C. A. M. de Haan, F. Reggiori, Nucleocapsid protein recruitment to replicationtranscription complexes plays a crucial role in coronaviral life cycle. J. Virol. 94 e01925-19 (2020). doi:10.1128/JVI.01925-19

24. M. C. Freeman, R. L. Graham, X. Lu, C. T. Peek, M. R. Denison, Coronavirus replicase-reporter fusions provide quantitative analysis of replication and 
replication complex formation. J. Virol. 88, 5319-5327 (2014). doi:10.1128/JVl.00021-14 Medline

25. R. L. Graham, A. C. Sims, R. S. Baric, M. R. Denison, The nsp2 proteins of mouse hepatitis virus and SARS coronavirus are dispensable for viral replication. Adv. Exp. Med. Biol. 581, 67-72 (2006). doi:10.1007/978-0-387-33012-9 10 Medline

26. M. J. Gadlage, J. S. Sparks, D. C. Beachboard, R. G. Cox, J. D. Doyle, C. C. Stobart, M. R. Denison, Murine hepatitis virus nonstructural protein 4 regulates virusinduced membrane modifications and replication complex function. J. Virol. 84 , 280-290 (2010). doi:10.1128/JVI.01772-09 Medline

27. R. N. Kirchdoerfer, A. B. Ward, Structure of the SARS-CoV nsp12 polymerase bound to nsp7 and nsp8 co-factors. Nat. Commun. 10, 2342 (2019). doi:10.1038/s41467-019-10280-3 Medline

28. M. Sevajol, L. Subissi, E. Decroly, B. Canard, I. Imbert, Insights into RNA synthesis, capping, and proofreading mechanisms of SARS-coronavirus. Virus Res. 194, 90 99 (2014). doi:10.1016/i.virusres.2014.10.008 Medline

29. L. Subissi, I. Imbert, F. Ferron, A. Collet, B. Coutard, E. Decroly, B. Canard, SARSCoV ORF1b-encoded nonstructural proteins 12-16: Replicative enzymes as antiviral targets. Antiviral Res. 101, 122-130 (2014). doi:10.1016/i.antiviral.2013.11.006 Medline

30. M. Gui, X. Liu, D. Guo, Z. Zhang, C. C. Yin, Y. Chen, Y. Xiang, Electron microscopy studies of the coronavirus ribonucleoprotein complex. Protein Cell 8, 219-224 (2017). doi:10.1007/s13238-016-0352-8 Medline

31. N. S. Ogando, T. J. Dalebout, J. C. Zevenhoven-Dobbe, R. W. A. L. Limpens, Y. van der Meer, L. Caly, J. Druce, J. J. C. de Vries, M. Kikkert, M. Bárcena, I. Sidorov, E. J. Snijder, SARS-coronavirus-2 replication in Vero E6 cells: Replication kinetics, rapid adaptation and cytopathology. J. Gen. Virol. 10.1099/jgv.0.001453 (2020). doi:10.1099/igv.0.001453 Medline

32. L. Kuo, C. A. Koetzner, P. S. Masters, A key role for the carboxy-terminal tail of the murine coronavirus nucleocapsid protein in coordination of genome packaging. Virology 494, 100-107 (2016). doi:10.1016/j.virol.2016.04.009 Medline

33. L. Caly, J. Druce, J. Roberts, K. Bond, T. Tran, R. Kostecki, Y. Yoga, W. Naughton, G. Taiaroa, T. Seemann, M. B. Schultz, B. P. Howden, T. M. Korman, S. R. Lewin, D. A. Williamson, M. G. Catton, Isolation and rapid sharing of the 2019 novel coronavirus (SARS-CoV-2) from the first patient diagnosed with COVID-19 in Australia. Med. J. Aust. 212, 459-462 (2020). doi:10.5694/mia2.50569 Medline

34. G. Wolff, R. W. A. L. Limpens, S. Zheng, E. J. Snijder, D. A. Agard, A. J. Koster, M. Bárcena, Mind the gap: Micro-expansion joints drastically decrease the bending of FIB-milled cryo-lamellae. J. Struct. Biol. 208, 107389 (2019). doi:10.1016/i.jsb.2019.09.006 Medline

35. W. J. H. Hagen, W. Wan, J. A. G. Briggs, Implementation of a cryo-electron tomography tilt-scheme optimized for high resolution subtomogram averaging. J. Struct. Biol. 197, 191-198 (2017). doi:10.1016/i.jsb.2016.06.007 Medline

36. S. Q. Zheng, E. Palovcak, J. P. Armache, K. A. Verba, Y. Cheng, D. A. Agard, MotionCor2: Anisotropic correction of beam-induced motion for improved cryoelectron microscopy. Nat. Methods 14, 331-332 (2017). doi:10.1038/nmeth.4193 Medline

37. A. Rohou, N. Grigorieff, CTFFIND4: Fast and accurate defocus estimation from electron micrographs. J. Struct. Biol. 192, 216-221 (2015). doi:10.1016/i.jsb.2015.08.008 Medline

38. Q. Xiong, M. K. Morphew, C. L. Schwartz, A. H. Hoenger, D. N. Mastronarde, CTF determination and correction for low dose tomographic tilt series. J. Struct. Biol. 168, 378-387 (2009). doi:10.1016/i.jsb.2009.08.016 Medline

39. A. S. Frangakis, R. Hegerl, Noise reduction in electron tomographic reconstructions using nonlinear anisotropic diffusion. J. Struct. Biol. 135, 239250 (2001). doi:10.1006/jsbi.2001.4406 Medline

40. J. R. Kremer, D. N. Mastronarde, J. R. Mclntosh, Computer visualization of threedimensional image data using IMOD. J. Struct. Biol. 116, 71-76 (1996). doi:10.1006/jsbi.1996.0013 Medline

41. D. Castaño-Díez, M. Kudryashev, M. Arheit, H. Stahlberg, Dynamo: A flexible, userfriendly development tool for subtomogram averaging of cryo-EM data in highperformance computing environments. J. Struct. Biol. 178, 139-151 (2012). doi:10.1016/i.jsb.2011.12.017 Medline

42. A. Kucukelbir, F. J. Sigworth, H. D. Tagare, Quantifying the local resolution of cryoEM density maps. Nat. Methods 11, 63-65 (2014). doi:10.1038/nmeth.2727 Medline
43. A. M. Anger, J. P. Armache, O. Berninghausen, M. Habeck, M. Subklewe, D. N. Wilson, R. Beckmann, Structures of the human and Drosophila 80 S ribosome. Nature 497, 80-85 (2013). doi:10.1038/nature12104 Medline

44. E. F. Pettersen, T. D. Goddard, C. C. Huang, G. S. Couch, D. M. Greenblatt, E. C. Meng, T. E. Ferrin, UCSF Chimera-A visualization system for exploratory research and analysis. J. Comput. Chem. 25, 1605-1612 (2004). doi:10.1002/icc.20084 Medline

45. Y. Harpaz, M. Gerstein, C. Chothia, Volume changes on protein folding. Structure 2, 641-649 (1994). doi:10.1016/S0969-2126(00)00065-4 Medline

46. S. H. Scheres, RELION: Implementation of a Bayesian approach to cryo-EM structure determination. J. Struct. Biol. 180, 519-530 (2012). doi:10.1016/i.jsb.2012.09.006 Medline

47. V. Lučič, A. Rigort, W. Baumeister, Cryo-electron tomography: The challenge of doing structural biology in situ. J. Cell Biol. 202, 407-419 (2013). doi:10.1083/icb.201304193 Medline

48. P. V'kovski, M. Gerber, J. Kelly, S. Pfaender, N. Ebert, S. Braga Lagache, C. Simillion, J. Portmann, H. Stalder, V. Gaschen, R. Bruggmann, M. H. Stoffel, M. Heller, R. Dijkman, V. Thiel, Determination of host proteins composing the microenvironment of coronavirus replicase complexes by proximity-labeling. elife 8, e42037 (2019). doi:10.7554/eLife.42037 Medline

49. B. W. Neuman, J. S. Joseph, K. S. Saikatendu, P. Serrano, A. Chatterjee, M. A. Johnson, L. Liao, J. P. Klaus, J. R. Yates 3rd, K. Wüthrich, R. C. Stevens, M. J. Buchmeier, P. Kuhn, Proteomics analysis unravels the functional repertoire of coronavirus nonstructural protein 3. J. Virol. 82, 5279-5294 (2008). doi:10.1128/JVI.02631-07 Medline

50. M. Bárcena, G. T. Oostergetel, W. Bartelink, F. G. Faas, A. Verkleij, P. J. Rottier, A. J. Koster, B. J. Bosch, Cryo-electron tomography of mouse hepatitis virus: Insights into the structure of the coronavirion. Proc. Natl. Acad. Sci. U.S.A. 106, 582-587 (2009). doi:10.1073/pnas.0805270106 Medline

\section{ACKNOWLEDGMENTS}

We are grateful to Mark Denison for sharing MHV- $\triangle 2-$ GFP3 and Leon Caly and Julian Druce for providing SARS-CoV-2 isolate betaCoV/Australia/VIC01/2020. We thank Natacha Ogando for BSL3 assistance, Frank Faas for technical support and Stuart Howes and Thomas Sharp for advice on image processing and helpful discussions. We thank Jürgen Plitzko and Miroslava Schaffer for introducing us to cryo-FIB-milling. EM tomography data of MHV-infected samples was collected at The Netherlands Centre for Electron Nanoscopy (NeCEN) with assistance from Christoph Diebolder and Rebecca Dillard. Funding: Access to NeCEN was made possible through financial support from the Dutch Roadmap Grant NEMI (NWO grant 184.034.014). D.A.A was supported by NIH grants R35GM118099, U19 Al135990 and S.Z. by the Howard Hughes Medical Institute. K.G. is supported by BMBF grant 05K18BHA, DFG grants EXC 2155, INST 152/772-1 and INST 777-1 FUGG. E.J.S. was supported by the \#wakeuptocorona crowdfunding initiative of Leiden University Fund (LUF) and LUMC Bontius Foundation, and by the SCORE project (European Union's Horizon 2020 research and innovation program, grant agreement 101003627). Author contributions: Conceptualization: M.B. A.J.K., E.J.S., G.W. Software: D.A.A., S.Z. Validation: M.B., G.W. Formal analysis: M.B., G.W. Investigation: M.B., A.W.M.J., U.L., R.W.A.L.L., G.W., J.C.Z.-D. Resources: K.G., A.J.K., E.J.S. Data Curation: M.B. R.I.K., G.W. Writing - original draft preparation: M.B., E.J.S., G.W. Writing review and editing: D.A.A., M.B., K.G., A.J.K., U.L., E.J.S., G.W. Visualization: M.B., R.I.K., R.W.A.L.L., G.W. Supervision: M.B., A.J.K., E.J.S. Project administration: M.B., E.J.S. Funding acquisition: A.J.K., E.J.S. Competing interests: Authors declare no competing interests. Data and materials availability: SARS-CoV-2 isolate betaCoV/Australia/VIC01/2020 and MHV- $\Delta 2$-GFP can be shared on request upon authorization from their original source (SARS-CoV-2: Leon Caly and Julian Druce, Doherty Institute, Melbourne, Australia; MHV- 22 -GFP3: Mark Denison, Vanderbilt University Medical Centre, Nashville, TN, USA). Cryo-EM maps have been deposited in the Electron Microscopy Data Bank under accession codes EMD-11514 (wt MHV-induced molecular pore), EMD-11515 (MHV- $\triangle 2$-GFP3-induced molecular pore). This work is licensed under a Creative Commons Attribution 4.0 International (CC BY 4.0) license, which permits 
unrestricted use, distribution, and reproduction in any medium, provided the original work is properly cited. To view a copy of this license, visit

https://creativecommons.org/licenses/by/4.0/. This license does not apply to

figures/photos/artwork or other content included in the article that is credited

to a third party; obtain authorization from the rights holder before using such

material.

\section{SUPPLEMENTARY MATERIALS}

science.sciencemag.org/cgi/content/full/science.abd3629/DC1

Materials and Methods

Supplementary Text

Figs. S1 to S9

References (33-50)

MDAR Reproducibility Checklist

Movies S1 to S3

22 June 2020; accepted 31 July 2020

Published online 6 August 2020

10.1126/science.abd3629 

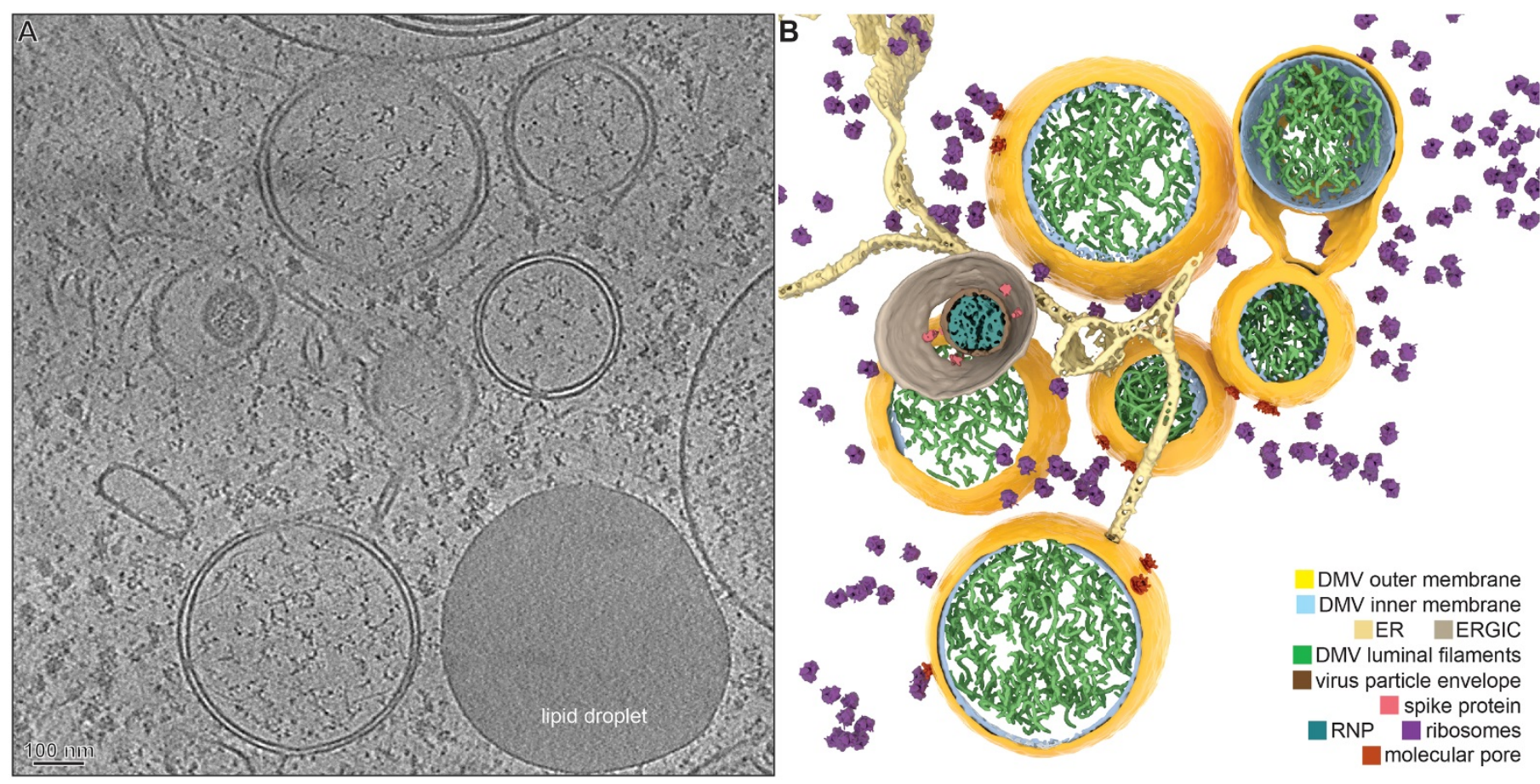

Fig. 1. Coronavirus-induced DMVs revealed by cryo-ET. (A) Tomographic slice ( $7 \mathrm{~nm}$ thick) of a cryo-lamella milled through an MHV-infected cell at a middle stage in infection. (B) 3D model of the tomogram with the segmented content annotated, see also movie S1. ERGIC, ER-to-Golgi intermediate compartment; RNP, ribonucleoprotein complex. 

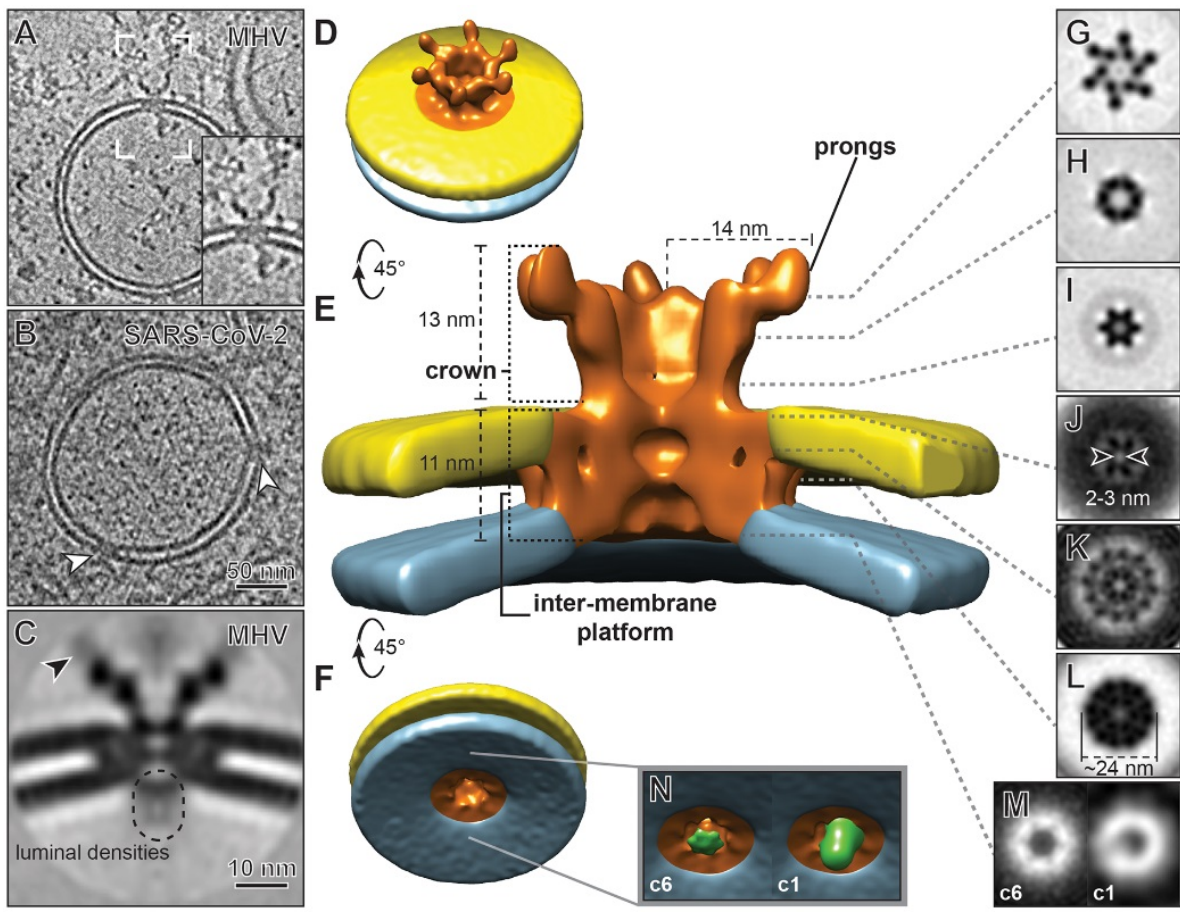

Fig. 2. Architecture of the molecular pores embedded in DMV membranes. Tomographic slices $(7 \mathrm{~nm}$ thick) revealed that pore complexes were present in both ( $\mathrm{A}$, inset) MHV-induced and (B) prefixed SARS-CoV-2-induced DMVs (white arrowheads). ( $\mathrm{C}$ to $\mathrm{L}$ ) 6 -fold symmetrized subtomogram average of the pore complexes in MHVinduced DMVs. (C) Central slice through the average, suggesting the presence of flexible or variable masses near the prongs (black arrowhead) and on the DMV luminal side. (D to F) Different views of the $3 \mathrm{D}$ surface-rendered model of the pore complex (copper-colored) embedded in the outer (yellow) and inner (blue) DMV membranes. (G to M) 2D cross-section slices along the pore complex at different heights (see also movie S2). ( $\mathrm{M}$ and $\mathrm{N}$ ) An additional density at the bottom of the 6 -fold symmetrized volume (c6, green) appeared as an off-centered asymmetric density in the unsymmetrized average (c1). 


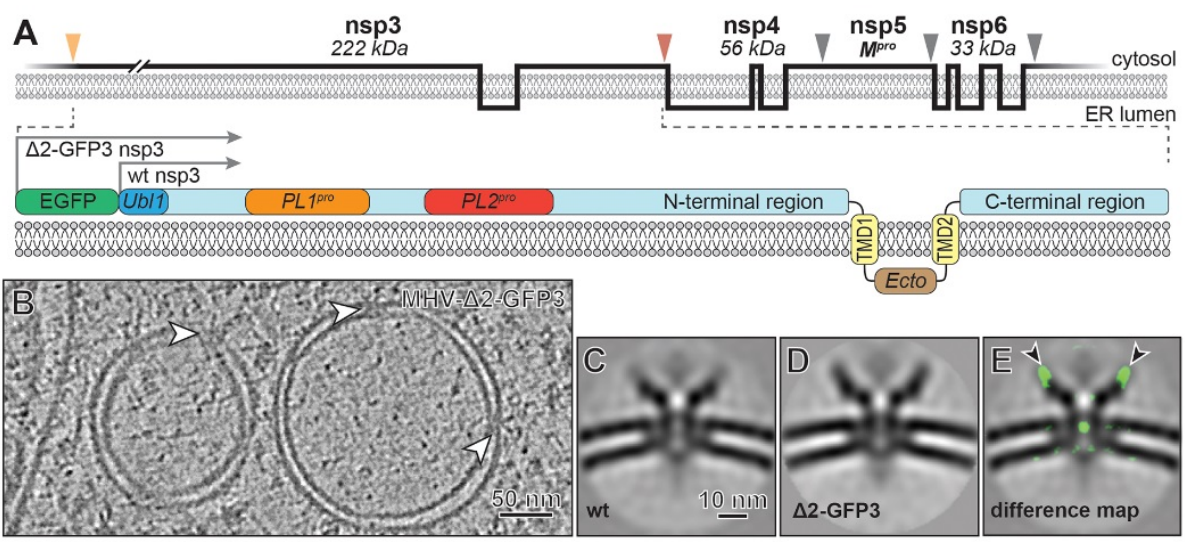

Fig. 3. The coronavirus transmembrane-protein nsp3 is a component of the pore complex. (A) Membrane topology (top) of MHV transmembrane nsps with protease cleavage sites indicated by orange $\left(P L 1^{\text {pro }}\right)$, red $\left(P L 2^{\text {pro }}\right)$ and gray $\left(\mathrm{M}^{\text {pro }}\right)$ arrowheads. (bottom) Detailed depiction of nsp3, showing some of its sub-domains and the position of the additional GFP moiety that is present in MHV- $\triangle 2-G F P 3$. (B) Tomographic slice of DMVs induced by MHV- $\triangle 2$-GFP3 with embedded pore complexes (white arrowheads). Comparison of the central slices of the 6-fold symmetrized subtomogram averages of the pore complexes in DMVs induced by (C) wt MHV and (D) MHV- $\triangle 2$-GFP3. (E) Density differences of 3 standard deviations between the mutant and the wt structures, shown as a green overlay over the latter, revealed the presence of additional (EGFP) masses in the mutant complex (black arrowheads, see also movie S3). PL ${ }^{\text {pro }}$, papain-like protease; $M^{\text {pro }}$, main protease. 


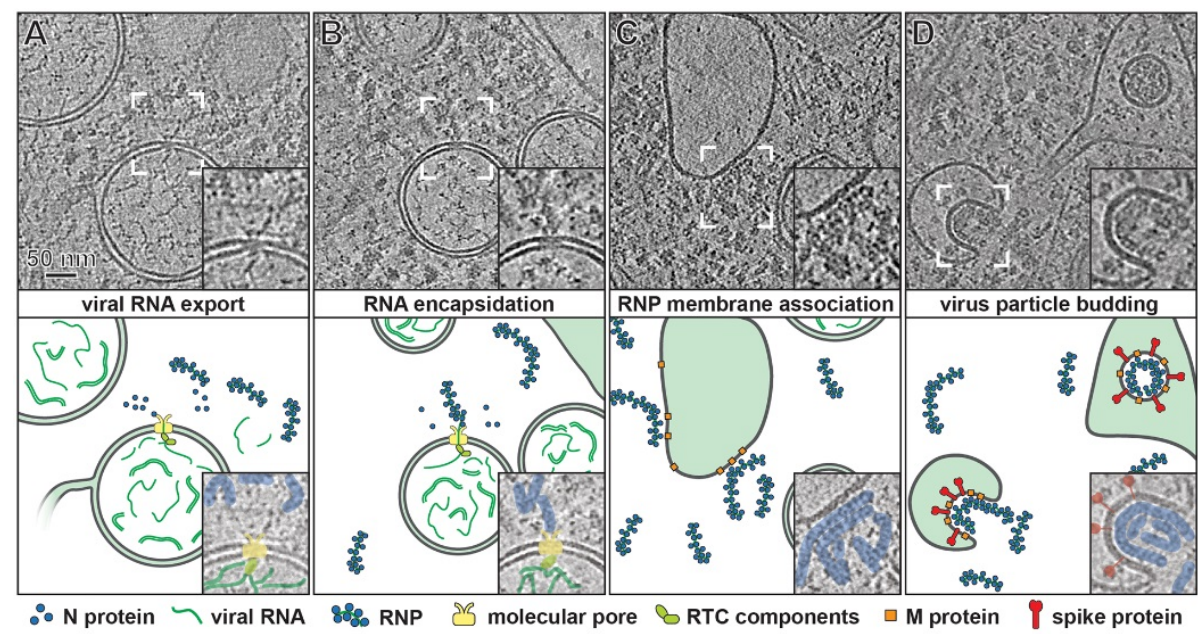

Fig. 4. Model of the coronavirus genomic RNA transit from the DMV lumen to virus budding sites. (Top) Tomographic slices from MHVinfected cells highlighting the respective steps in the model (bottom). (A) The molecular pore exports viral RNA into the cytosol, (B) where it can be encapsidated by N protein. (C) Cytosolic RNPs then can travel to virus assembly sites for membrane association and (D) subsequent budding of virions. 